Acknowledgements

The author wishes to thank Roger Ingham (University of Southampton), Brook Advisory Centres, Pauline Deeks (Public Health Laboratory Service), Alan Hervé (Office for National Statistics), Ford Hickson (Sigma Research) and Lesz Lancucki (Department of Health) for their great help in providing data and answering queries.

Statements on funding and competing interests

Funding. None identified.

Competing interests. None identified.

References

1 Royal Commission on Venereal Disease. Final report of the commissioners (1st edn). London: Her Majesty's Stationery Office, 1916.

National Health Service Act 1977, c.49.

3 International Planned Parenthood Federation. Male involvement in family planning: report of an IPPF staff consultation. London: IPPF, 1984.

4 Office for National Statistics. Annual update: births in 2000 and conceptions in 1999, England and Wales. Popul Trends 2001; 106: 69-72.

5 PHLS, DHSS\&PC and Scottish ISD(D)5 Collaborative Group. Trends in sexually transmitted infections, 1990-1999. London: Public Health Laboratory Service, 2000.

6 Department of Health. Better prevention. Better services. Better sexual health. The National Strategy for Sexual Health and HIV. London: Department of Health, 2001.

7 Department of Health. NHS contraceptive services, England: 2000-01. Bulletin 2001/27. London: Department of Health Statistics Division 2B, 2001

8 Peckham S, Ingham R, Diamond, I. Teenage pregnancy: prevention and programmes. Southampton: University of Southampton, Institute for Health Policy Studies and Centre for Sexual Health Research, 1996.

9 Aggleton P, Chalmers H, Daniel S, et al. Promoting young people's sexual health. A compendium of family planning service provision for young people. London: Health Education Authority, 1996.

10 Brook Advisory Centres. Brook Advisory Centres Annual Report. London: Brook Advisory Centres, annual publication.

11 Frater A. Young men at Brook Advisory Centres. London: Family
Planning Association, 1985

12 Office for National Statistics. Living in Britain. Results from the 1998 General Household Survey. London: The Stationery Office, 1999

13 South Downs Health NHS Trust. Annual Report on Young People's Clinics. Brighton: Morley Street Health Centre, 1993.

14 Walsh J. Family planning provision in genitourinary medicine clinics: a quiet revolution. Br J Fam Plann 1996; 22: 27-30.

15 Wellings K, Field J, Johnson AM, et al. Sexual behaviour in Britain: the National Survey of Sexual Attitudes and Lifestyles. London: Penguin Books Ltd, 1994.

16 Johnson AM, Wadsworth J, Wellings K, et al. Who goes to sexually transmitted disease clinics? Results from a national population survey. Genitourin Med 1996; 72: 197-202.

17 Weatherburn P, Stephens M, Reid D, et al. Vital statistics. Findings from the National Gay Men's Sex Survey, 1999. Portsmouth: University of Portsmouth, Sigma Research, 2000.

18 Department of Health. Prescription cost analysis: England 1998. London: Department of Health, 1999.

19 National Health Service Executive. Guidelines for reviewing family planning services: guidance for regions. London: NHSME, 1992.

20 All cited in Burton RA. Patients' evaluation of a GP condom scheme. $\mathrm{MSc}(\mathrm{Ed})$ thesis, Faculty of Educational Studies, University of Southampton, Southampton, 1996.

21 Parham A, Turner B, Yarwood J. A survey of condom distribution throughout general practice in Camden and Islington. Health Educ J 1995; 54: 143-149.

22 Pengilley L, Kay R. Condom use and distribution from general practice - a study from Oxfordshire. Br J Fam Plann 1995; 20 $108-111$.

23 Davidson N, Lloyd T. Working with heterosexual men on sexual health. Men's Sexual Health Project March 1993 Audit. London: Health Education Authority, 1994.

24 Jones M. Audit of condom issuing in Eastbourne sexual health clinic. Br J Fam Plann 1999; 25: 110-111.

25 Office of Population Censuses and Surveys. Morbidity Statistics from General Practice. Fourth National Study 1991-1992. MB5: 3. London: HMSO, 1995.

26 Djuretic T, Catchpole M, Bingham JS, et al. Genitourinary medicine services in the United Kingdom are failing to meet current demand Int J STD AIDS 2001; 12: 571-572.

\title{
Promoting sexual health services to young men: findings from focus group discussions
}

\author{
Steve Pearson, BSc, PhD, Researcher, Centre for Sexual Health Research, University of Southampton, Southampton, UK
}

Correspondence: Dr S Pearson, Centre for Sexual Health Research, Faculty of Social Sciences, University of Southampton, Highfield, Southampton SO17 1BJ, UK. Tel: +44 (0) 2380597770 . Fax: +44 (0) 2380593844.

E-mail: pearson22s@yahoo.co.uk

(Accepted 10 March 2003)

Journal of Family Planning and Reproductive Health Care 2003; 29(4): 194-198

\begin{abstract}
Context. Recently, increasing interest has been shown in men's reproductive health, sexual behaviour and use of contraception. As the majority of sexual health service clients are female, however, little research has been done on the characteristics and needs of male clients.

Objective. Using data from focus group discussions, this paper considers whether young men need sexual health services, whether current services are appropriate and accessible, and what promotion strategies might increase service uptake.

Design. Nine focus group discussions with 75 men aged 13-21 years at different locations in England.

Results. Young men's decision-making around sexual health may involve seeking advice from a close friend, but is less likely in some male social groups. Use of services by young men is most likely to obtain free condoms, or to remedy a crisis situation. While a young man is becoming familiar with obtaining condoms from a service, the need for a quick, straightforward service seems important. The stereotypical view within the groups was that sexual health
\end{abstract}

services are women-oriented. However, suggestions are given to make services more youth-and male-friendly. Promotion should aim to increase awareness and advance a positive image of a sexual health service.

Discussion and conclusions. Effective promotion campaigns (designed with the input of local young men), combined with appropriate and accessible services, should help to increase service use among young men.

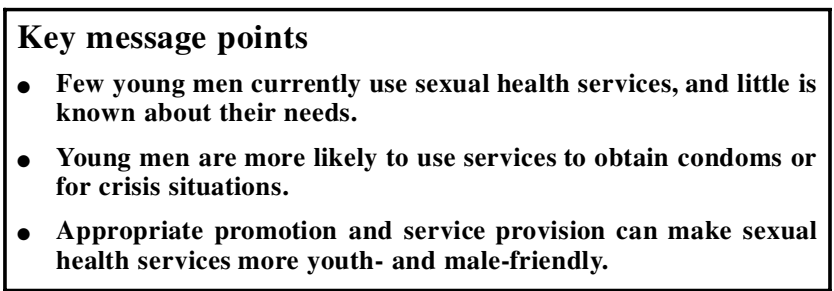

\section{Context}

The past two decades have seen increasing interest in the role men play in sexual relationships, use of contraception, and as clients of sexual health services. The emergence of 
HIV in the mid-1980s prompted research into condom use, and hence the role of male partners in contraceptive use. A continuing high rate of teenage pregnancy ${ }^{1}$ and rising rates of sexually transmitted infections (STIs) ${ }^{2}$ in the UK suggest that men need to be targeted to improve both men's and women's sexual health.

During the 1990s, men's use of family planning clinics (FPCs) and young people's sexual health clinics to obtain condoms has substantially increased. ${ }^{3}$ However men are still minority users. In 2000-2001, men accounted for 7\% of FPC clients, ${ }^{4}$ and $11 \%$ of Brook Advisory Centres clients. ${ }^{5}$ Only genitourinary medicine (GUM) clinics have approximately equal numbers of men and women attending. ${ }^{2}$

As the majority of sexual health clients attending FPCs and general practice are female, previous research on male clients is sparse. Three studies in the 1980s highlighted barriers men face in obtaining condoms from FPCs. ${ }^{6-8}$ Men's knowledge of sexual health services has been found to be lower than women's. ${ }^{9,10}$ Evaluations of men-only sessions in FPCs ${ }^{11,12}$ and a men-only drop-in sexual health service $^{13}$ have shown some success, although intensive promotion campaigns were needed. Several studies have asked male clients attending GUM clinics their views on the provision of services. ${ }^{14-16}$ In particular the service needs of gay and bisexual men have received attention. ${ }^{17}$

The importance of effective promotion strategies to increase knowledge of a sexual health service and encourage service uptake among young people is clear. ${ }^{18,19}$ Services have reported using posters, leaflets, flyers, booklets and outreach as methods of promotion. ${ }^{20,21}$ When clients themselves are asked, the most important source of information about a service is 'word of mouth', usually from friends. ${ }^{13,22}$

\section{Objective}

A key element of the National Strategy for Sexual Health and HIV $^{23}$ is provision of appropriate, accessible sexual health services for those who need them. Given that sexual health services currently are under-utilised by young men, this raises three important questions. Do young men need these services? Are the services appropriate and accessible? What promotion strategies would encourage service use? This paper addresses these questions using data from focus group discussions with young men in England.

\section{Design}

Data were collected from a study aiming to provide sexual health purchasers and providers with information to help promote their services to young people, thus increasing their appropriateness, accessibility and use. ${ }^{24}$ Focus group discussions were held with young people at locations around England. As part of this author's doctorate thesis, ${ }^{25}$ data from the male focus groups were re-analysed to provide a focus solely on men.

In a focus group, emphasis is placed on how the group interacts in the discussion. ${ }^{26}$ Agreement, disagreement, challenges and interjections can force respondents to clarify, justify, re-examine or retract their stated views. The flexibility and depth of the focus group allows respondents to provide detail in their own language and frame of reference, and to identify topics of importance and interest to themselves. ${ }^{27} \mathrm{As}$ 'word of mouth' is an important route through which information on sexual health services is shared, impressions and stereotypes of services should emerge in a group discussion. However, weaknesses of focus groups should be acknowledged. In front of the group, some respondents may report humorous, socially desirable or prestigious responses, but not their 'true' views. Equally, some respondents may be unwilling to report personal or sensitive information.
Focus groups were conducted at nine sites around England to represent urban, semi-urban and rural locations. Various recruitment methods were used including direct contact through sexual health services, outreach work, posters and 'snowballing' (that is, asking initial participants to recommend others). Groups took place in school and college classrooms, youth clubs and drop-in centres. The nine focus groups involved 75 men aged 13-21 years, with a median age of 17 years. Two-thirds of the men were still in education, with the remainder looking for work or employed.

All focus groups were audio recorded and transcribed. Transcribing was done near verbatim, with important speech utterances and contextual comments included. Analysis of the data followed a four-stage process: ${ }^{28}$ data formatting, data organising, generating categories, themes and patterns, and testing emerging hypotheses against the data. Quotations are used to illustrate and illuminate the findings being discussed, with $\mathrm{R}$ indicating speech by an individual respondent, and $\mathrm{M}$ the moderator.

\section{Results}

\section{Sexual health decision-making}

In the focus groups, seven hypothetical dilemmas were introduced to stimulate discussion on how young men make decisions around sexual health. Two options emerged from the discussions: whether to discuss the problem with anyone, and whether to use a service for information, advice or treatment.

For the first option, discussing a personal and sensitive sexual health dilemma can entail risks for the teller. For example, concerns were raised that some male friends would not take a dilemma seriously, make fun of the young man, or indiscreetly tell other people. The need to preserve social standing in front of peers may prohibit discussion of issues undermining status, as shown in the following extract discussing virginity.

R: "It's harder for boys 'cause they've got images and stuff. You don't want to ruin your images with your mates."

\section{M: "What kind of image would this be?"}

$\mathrm{R}$ : “Don't know, sort of a macho image isn't it, you've got."

R: "'Cause if you walk up to a friend and say, 'Look, I'm going to shag me girlfriend and I'm a virgin, what am I going to do about it?' they're going to laugh at you."

$\mathrm{R}$ : "So there's no point speaking to your mates, is there?" (laughter) (Milton Keynes group)

The open and honest discussion of personal sexual health dilemmas is taboo within some male social groups, only occurring in private between close, trusted friends. This prohibition was not associated with women's friendship groups; some respondents talked enviously of the perceived ease with which young women can have serious discussions with female friends. Telephone helplines were suggested as an appropriate source of sexual health advice for men, as the anonymity and lack of faceto-face contact facilitates more open discussion.

Aspects of masculinity may hinder young men from seeking advice and information from a sexual health service. These include the perceived need for a young man to be highly knowledgeable about sex, and unwillingness to expose weakness by admitting to needing help. Although most respondents recognised that sexual health services offer advice and information, most reported that they would not use this service. From the discussion of dilemmas, young men considered using services for two 
main reasons: to obtain condoms or to remedy a crisis situation. For obtaining condoms, getting relatively expensive items free was an attractive proposition, but associated costs can outweigh this advantage. Travel, for example, can be costly for a young man using public transport to attend a service in a city or town centre.

$\mathrm{R}$ : "No one can really be bothered to sit on a bus for ages and spend their money just to come up city."

R: “To get some free rubbers and go home." (laughter)

$\mathrm{R}$ : "It's not worth the hassle."

R: "You might as well just go in the corner shop and buy a packet; it's the same money as you're paying to come up here."

(Milton Keynes group)

Another cited cost was the hassle involved in procuring condoms. In the following extract, some respondents had considered obtaining condoms from a service, but were dissuaded by the need to provide personal details.

$\mathrm{R}$ : "You have to fill those forms out as well, that's why we never went, they wanted personal stuff."

$\mathrm{R}:$ "What about?"

$\mathrm{R}$ : “Can't you refuse them?"

$\mathrm{R}$ : "They put you down on a computer and then you get the condoms."

(Wirral group)

However, respondents in other groups were aware that some services allow false names and addresses. The second main reason for service use, to remedy a crisis situation, is when a young man realises his sexual health requires immediate attention. As this respondent explains, symptoms of an STI are one such situation.

\section{M: "And do you think people would be happy to go to the} clinic in that situation?"

$\mathrm{R}$ : "I think you might have no choice in a way. Yeah, if they think they might have caught something, I think no matter what they might feel it's important to find out."

(Gosport group)

\section{Service image}

Based upon the respondents' answers to a short anonymous questionnaire, the focus groups included both users and nonusers of sexual health services. Non-users reported their perceptions of a service based upon any prior knowledge, assumptions and intuitive guesses. Combining these perceptions with the experiences of service users produces information on what image a service should aim to promote. Four themes are discussed below: client characteristics, service atmosphere, staff and confidentiality.

First are the characteristics of clients a service aims to attract. A common finding from the groups was that although sexual health services were recognised as being available to both sexes, they are more oriented towards, and likely to be used by, women. Respondents gave three explanations for this bias:

- Services offered are women-oriented (e.g. contraceptive provision, pregnancy tests, advice and information).

- As only women are at risk of conceiving, they have greater need of services.

- Women take greater precautions in sexual activity than men.

The name of a service also suggests the nature of its clients. This group interpreted 'family planning' as implying that the service was aimed at older couples in stable relationships.
M: "You don't think people your age would go to the family planning clinic?"

$\mathrm{R}$ : "Not yet, not until we started family planning, and that's when we'd go, basically."

R: "You've got to settle down. The girl who you're with, you've got to be with her for at least 6 years."

R: "Settling down - that's when you're planning."

(Manchester group)

Two other examples of the influence of a service's name: 'drop-in' was interpreted as "it's just for old people if they just want to drop in and have a cup of tea" (Milton Keynes young man). Another group jokingly surmised that as the initials spell 'gum', a GUM clinic is involved with dentistry.

A second theme is service atmosphere. At one extreme are services thought to be 'cold', clinical and generally unfriendly. Respondents often perceived FPC and GUM clinics in this way, a perception reinforced by their medical titles. Young people's sexual health services were given mixed impressions, although most were rated as fairly friendly and welcoming. Although respondents seemed to prefer this type of atmosphere, concerns were expressed if a service is too friendly and keen to involve a client. In the following extract, the group constructed a metaphor of a police interrogation for a service visit.

$\mathrm{R}$ : "They take you into this little room and put you on a bean bag and then ...” (laughter)

$\mathrm{R}$ : "And they lock the door and say, 'Do you want to talk about it?",

$\mathrm{R}$ : "It's a bit of an intimidating atmosphere for a 14year-old 'cause like there's loads of people sat round having coffee there, and then they take you off to a little room and like there's a wooden chair in there, it's crude, some guy walks round ....” (laughter)

$\mathrm{R}$ : “A spotlight shines in your face."

$\mathrm{R}$ : "Another mirror hanging on the wall, two-way mirror hanging on the wall."

R: "Yeah, and then they just like say, 'What do you want?' and you say, 'Can I have some condoms real quick, I want to get out of here'."

M: "So you're saying it's not really a friendly atmosphere?"

$\mathrm{R}$ : "Yeah, it's over friendly though; it makes you want to cringe."

(Gosport group)

Contrasting ideas are evident; the service has features associated with a friendly and welcoming atmosphere (people talking, having coffee, bean bags). However, the humorous metaphor of the interrogation implies the approach is too involving for the simple requirement of obtaining condoms. Some respondents preferred minimal contact time, with no personal questioning or counselling.

A third theme is service staff. Respondents who had never visited a sexual health service had a stereotypical image of a staff member as an old, patronising and judgmental woman. The following extract discusses family planning clinic staff.

$\mathrm{R}$ : "The staff are old nurses who leer at you because you're young."

R: "You shouldn't be doing that at your age, sonny."

$\mathrm{R}$ : "A big fat matron like in the 'Carry On' films." (laughter) 
While preference was expressed for staff with the experience and expertise associated with age, some respondents also wanted staff youthful enough to understand young people's lifestyles, and without morally disapproving beliefs associated with older generations.

The fourth theme is confidentiality. A concern raised within groups was the confidentiality of a visit to a general practitioner, that is, the doctor (or nurse or receptionist) would not tell anyone (particularly the young man's parents) about the visit's purpose or outcome. If the doctor knew the young man's parents (e.g. in a small, rural community), this became more of a concern. Groups disagreed on whether doctors legally are required to maintain confidentiality. Overall, confidentiality appeared less of an issue among young men than identified from studies of young women. 9,22 This may be because young men are less concerned about being identified as sexually active, or because they are less likely to use a service for counselling when confidential information may be revealed.

\section{Service promotion}

Important elements of a promotion strategy for a sexual health service include choosing the methods of promotion, designing the style and content, and locating the material. Two contexts for locating material emerged from the discussions: locations where a young man actively seeks information on a service (e.g. a telephone directory), and passive locations where a young man is exposed inadvertently to promotional material (e.g. a poster). Most discussion in the groups revolved around the latter, but active locations should not be neglected. Locations where respondents expected information about a service to be available included libraries, general practice waiting rooms, and notice boards in schools, colleges and youth clubs.

Underlying both passive and active locations is the need for the material to be viewed discretely and confidentially. Two ways to do this are to use private (e.g. a sticker on the back of a toilet door) or universal (e.g. a poster in a shopping centre) locations. Discretely viewing material in a universal location can still be difficult, however, as explained by this group discussing a poster with the word 'sex' displayed prominently.

$\mathrm{R}$ : "If you saw that poster in the street and there was a crowd of people and you went over and looked at it, you'd get the piss took out of you 'cause you're looking at a sex poster.”

$\mathrm{R}$ : “You wouldn't have the courage to look at that along the street, would you?"

$\mathrm{R}$ : "I suppose if I was stood there waiting for something and there was a poster on the wall, then I would have a look. Like at a bus stop or something."

R: "I wouldn't just stop and read it, I think I'd just pass it on, just leave it there and walk past it."

(Manchester group)

Groups disagreed on whether materials should focus on positive or negative aspects of service provision. One argument was that promoting aspects with negative connotations (e.g. using the words 'problems' and 'diseases') results in a pessimistic, gloomy message. As illustrated by this discussion on using beer mats for promotion, this is inappropriate if the material is located in an environment associated with enjoyment.

M: "Beer mats were mentioned; would that work?"

$\mathrm{R}$ : “No, it would put you off your pint, wouldn't it?"
R: "You're out with your mates on a Saturday night. You're sitting there and you're having a good laugh and you pick up your beer mat, and you go [mimes action of reading beer mat], everyone will be cracking on, won't they?"

R: "Yeah, and you go out and have a few drinks like, and you're dead set on pulling a woman, but when you see like 'herpes' and all that you think, 'No, can't be bothered now'."

(London group)

However, a contrasting argument proposed in other groups was that an effective way to increase service uptake by young men was to highlight sexual risks, and how use of a service can mitigate those risks. Suggested risks to highlight included HIV/AIDS, other STIs and unintended conceptions.

Instead of purely giving information, respondents felt that successful promotional material should match standards of style-conscious consumer advertising. As promotional material may be located where it competes for a person's attention, effective material needs to be fashionable and eye-catching. These aspects can be more important than the information included.

\section{M: "Does this poster give enough information or does it tell you ....?"}

$\mathrm{R}$ : "It doesn't matter, it could have all the information in the world on it but you're not going to read it 'cause it's so boring."

R: "Yeah, you need something short and to the point." (Cumbria group)

Groups generally liked the use of humour in promotion, provided it was funny and used appropriately. Humour helps to overcome any embarrassment around sex, and ensure the material is noticed and remembered. This extract discussed an old poster with a picture of trouser flies and the slogan 'Flies can spread diseases'.

$\mathrm{R}$ : "And the funniness of that one, 'Flies can spread diseases' - you see that bit and then you want to read the rest of it."

$\mathrm{R}$ : “Using humour to get it across."

$\mathrm{R}$ : "Sex is generally regarded as very embarrassing. So if you can get people to laugh about it, they're going to be more open about it and read it."

R: "You feel more comfortable if you're enjoying yourself and you're joking, don't you?"

(Milton Keynes group)

Using images in visual material was approved, provided the images related to and enhanced the promotional message. For example, an image of young people ensures the material is noticed, suggests the service is aimed at young people, and reinforces a welcoming and friendly atmosphere. However, the young people in the image need to be chosen carefully. Preference was expressed for 'normal' young people as opposed to models. Respondents were quick to notice and criticise oldfashioned clothing or hairstyles. Showing young people talking together was reported as a positive image for a service offering advice and information.

R: "This photo would be good for a drop-in service 'cause it's a very informal chat; it's a chat around the table, sort of thing."

$\mathrm{R}$ : "This is the kind of thing that happens as well like, you see a bird that's passing, and you might just give her a nice smile and chat to her." (London group) 
Most groups preferred images of groups of young men and women as opposed to single portraits. An image of only young men was unpopular as it suggested the service was aimed at gay men. One grouping receiving positive comments was male-female couples, although not posing too intimately as to imply the service only catered to people in steady relationships.

\section{Discussion and conclusions}

A qualitative research method such as focus groups provides only one perspective on a topic, and findings could be validated further by triangulation with quantitative methods. Due to the group context of a focus group, for example, it is likely that private decision-making around sexual heath services was not fully reported. This paper gives an in-depth exploration of the impressions of sexual health services among a small group of young men, but findings should not be taken as representative of all young men in the study areas. Nevertheless, the group discussions produced valuable information to help explain the current under-utilisation of sexual health services by young men. Factors on both the supply and demand sides of this equation need addressing.

On the demand side, the respondents considered using services mostly for routine or crisis situations. While this finding may initially be viewed negatively, it can be argued that most young women attend sexual health services in similar situations. The discussion of dilemmas illuminated ways in which young men think about, and manage, their sexual health. Although the stereotypical view is that men are reticent in discussing their health, many respondents identified people they felt they could approach. Although taboos on discussing personal and 'non-masculine' topics exist in some male social groups, this is not the only forum available. Scope seems to exist, therefore, for some young men to use services for advice and information.

On the supply side, aspects of service provision that do and do not appeal to young men have been identified; service management and staff can use these to help determine the image a service should present in promotion and day-to-day operation. If desired, potential exists for services to be made more youth- and male-friendly. While a young man is becoming familiar with obtaining condoms, the need for a quick and straightforward service seems important. Opportunities for a young man to ask questions should be available, but he should not feel pressurised to engage in more personal counselling.

Promotion should aim to increase awareness and advance a positive image of a sexual health service, areas most focus groups identified as in need of improvement. Designing an effective promotion campaign requires the input of local young men to test out material and identify suitable locations. While promotional material needs to contain basic information about a service, the overall style and design of material may be more important to catch a person's attention and promote a positive image. Particularly for visual media, sexual health service promotion may be judged alongside neighbouring consumer advertising. Therefore, the material needs to match advertising's high standards of style, appearance and content in order for promotion to be effective.

Finally, the importance of 'word of mouth' as a source of information about sexual health services is reconfirmed. This is a more limited channel of communication among young men than young women, as more young women use services and therefore more information and impressions are available to be conveyed. Once a core of young men attends a service and passes on (hopefully) positive comments to male peers, a 'snowball' effect should result in increased male service uptake.
Acknowledgements

The author wishes to thank University of Southampton former colleagues Deborah Cornah, Ian Diamond, Marisa Hyde, Roger Ingham and Stephen Peckham who, together with the author, were the research team who collected the original data.

\section{Statements on funding and competing interests}

Funding. The author has previously received funding from Brook Advisory Centres and the former Health Education Authority.

Competing interests. None identified.

References

1 Office for National Statistics. Annual update: births in 2000 and conceptions in 1999, England and Wales. Popul Trends 2001: 106: 69-72.

2 PHLS, DHSS \& PC and Scottish ISD(D)5 Collaborative Group. Trends in sexually transmitted infections, 1990-1999. London: Public Health Laboratory Service, 2000.

3 Pearson S. Men's use of sexual health services. J Fam Plann Reprod Health Care 2003; 29(4): 190-194.

4 Department of Health. NHS contraceptive services, England: 2000-01. Bulletin 2001/27. London: Department of Health Statistics Division 2B, 2001

5 Brook Advisory Centres. Brook Advisory Centres Annual Report 2000-01. London: Brook Advisory Centres, 2001.

6 Howard G, Whittaker I. Difficulties in obtaining condoms on the NHS. Br J Fam Plann 1981; 7: 12-15.

7 Chambers J. Condom survey. In: Birth Control Trust, Men, sex and contraception. London: Family Planning Association, 1984

8 Duncan P. Odd man out. Nurs Times Nurs Mirror 1987; 83(2): 39-40.

9 Cooper P, Diamond I, Gould C, et al. Choosing and using contraceptives: consumers' experiences in Wessex. Southampton: University of Southampton, Department of Social Statistics, 1992.

10 Hirst J. Teenagers and risk: understanding and affirmation as tools for effective education. The AIDS Letter 1994; 45: 1-3.

11 Elton P, Blair A. A contraceptive service for men. Br J Fam Plann 1987; 13: 10-11

12 Davidson N, Lloyd T. Working with heterosexual men on sexual health. Men's Sexual Health Project March 1993 Audit. London: Health Education Authority, 1994

13 Jewitt C. Brook and men evaluation report: developing young men's sexual health initiatives. London: Health First; 1995.

14 Munday PE. Genitourinary medicine services; consumer's views. Genitourin Med 1990; 66: 108-111.

15 Monteiro E. An audit of patient's views in Yorkshire genitourinary medicine clinics. Int J STD AIDS 1995; 6: 217-221.

16 Evans D, Farquhar C. An interview based approach to seeking user views in genitourinary medicine. Genitourin Med 1996; 72: 223-226.

17 Sigma Research. Quality indicators for GUM services to gay men in England. Portsmouth: University of Portsmouth, Sigma Research, 1999.

18 Mackereth C, Forder J. Assessing the sexual health needs of young people. Health Visitor 1996; 69: 144-146.

19 Social Exclusion Unit. Teenage pregnancy. London: The Stationery Office; 1999.

20 Aggleton P, Chalmers H, Daniel S, et al. Promoting young people's sexual health. A compendium of family planning service provision for young people. London: Health Education Authority, 1996.

21 Peckham S, Ingham R, Diamond I. Teenage pregnancy: prevention and programmes. Southampton: University of Southampton, Institute for Health Policy Studies and Centre for Sexual Health Research, 1996.

22 Allen I. Family planning and pregnancy counselling projects for young people. London: Policy Studies Institute, 1991.

23 Department of Health. Better prevention. Better services. Better sexual health. The National Strategy for Sexual Health and HIV. London: Department of Health, 2001.

24 Pearson S, Cornah D, Diamond I, et al. Promoting young people's sexual health services. Report commissioned by the Health Education Authority. London: Brook Advisory Centres, 1996.

25 Pearson S. Young men's sexual behaviour and use of contraception. Doctoral dissertation, University of Southampton, Southampton, UK, 2000.

26 Kitzinger J. The methodology of focus groups: the importance of interaction between research participants. Sociol Health Illn 1994; 16: 103-121.

27 Morgan DL. Focus groups as qualitative research. Sage University Paper Series on Qualitative Research, vol. 16. Newbury Park, CA: Sage, 1988.

28 Marshall C, Rossman GB. Designing qualitative research (2nd edn). Newbury Park, CA: Sage, 1994. 